\title{
Analysis of the reasons for inefficiencies of grain sowing and harvesting processes
}

\author{
Victor Kataev ${ }^{1}$, Ilia Markvo ${ }^{*}$, , Kaprel Khubiian ${ }^{1}$, and Elena Zubrilina ${ }^{1}$ \\ ${ }^{1}$ Don State Technical University, Gagarin sq., 1, Rostov on Don, 344003, Russia
}

\begin{abstract}
The efficiency of sowing and harvesting processes in agriculture is one of the most important components of the success of an agricultural firm. Natural and climatic conditions typical for the majority of Russian agricultural territories impose restrictions on the timing and the fundamental possibility of sowing and harvesting. Therefore, the low efficiency of sowing and harvesting processes leads to a corresponding decrease in the volume of crop production. A number of works [1-4] consider various approaches to increasing the efficiency of sowing and harvesting, however, a systematic approach to the management of agricultural company processes requires the identification of the most significant reasons for the decrease in the efficiency and addresses as a priority their elimination (or reduction in the strength of their influence). The paper analyzes the reasons for the inefficiencies of sowing and harvesting processes and provides recommendations for reducing the impact of these reasons.
\end{abstract}

\section{Introduction}

This paper considers and summarizes the results of observations of processes of grain crops sowing and harvesting in six agricultural enterprises in the South of Russia (Rostov region) in the agricultural years 2019-2020. The total area allocated for the cultivation of grain crops (wheat and barley) in the observed enterprises is about 15,000 hectares. During the sowing work, 34 units of the equipment (a tractor and a seeder) were involved, and during harvesting, 53 combine harvesters manufactured by the Rostselmash plant were used.

Grain crops sowing and harvesting are the most important operations in the production of crop products, while the technologies and means of implementing these processes differ significantly. Therefore, the analysis of the reasons for the decrease in efficiency was performed separately for each group of processes.

The efficiency of the seeders depends on ensuring a uniform distribution of seeds over the seedling environment zone, quick and convenient setting on a specified seeding rate, compliance with the established seeding rate, adaptation to different size and quality of the seed, minimal damage to the sown seeds. In order to obtain a high and stable yield, the seeders must provide these agrotechnical parameters. One of the key working parts of the seeders is the seeding unit. Figure 1 schematically shows the main factors leading to inefficiencies of seeding processes.

\footnotetext{
*Corresponding author: iluhan_markvo@mail.ru
} 


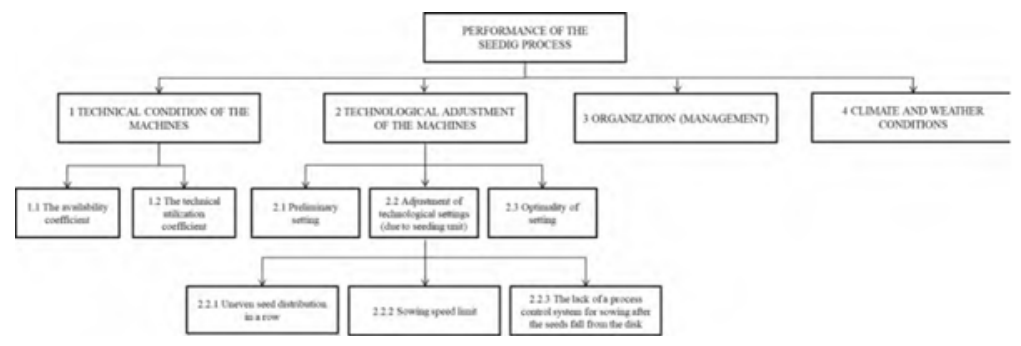

Fig. 1. The reasons for the inefficiencies of seeding processes.

The main drawbacks of modern seeding units are the limitation associated with high sowing speed, the existence of the oblique impact and the inversion of the seeds, which adversely affects exact positioning of the seeds in the soil, and as a result, there is uneven distribution of the seeds in a row and the complete lack of opportunity to control the sowing process after the seeds have fallen from the disk [1-6]. Efficiency can be increased by introducing an automatic system for control and monitoring of sowing quality [7-9] into the seeder unit as shown in figure 2 .

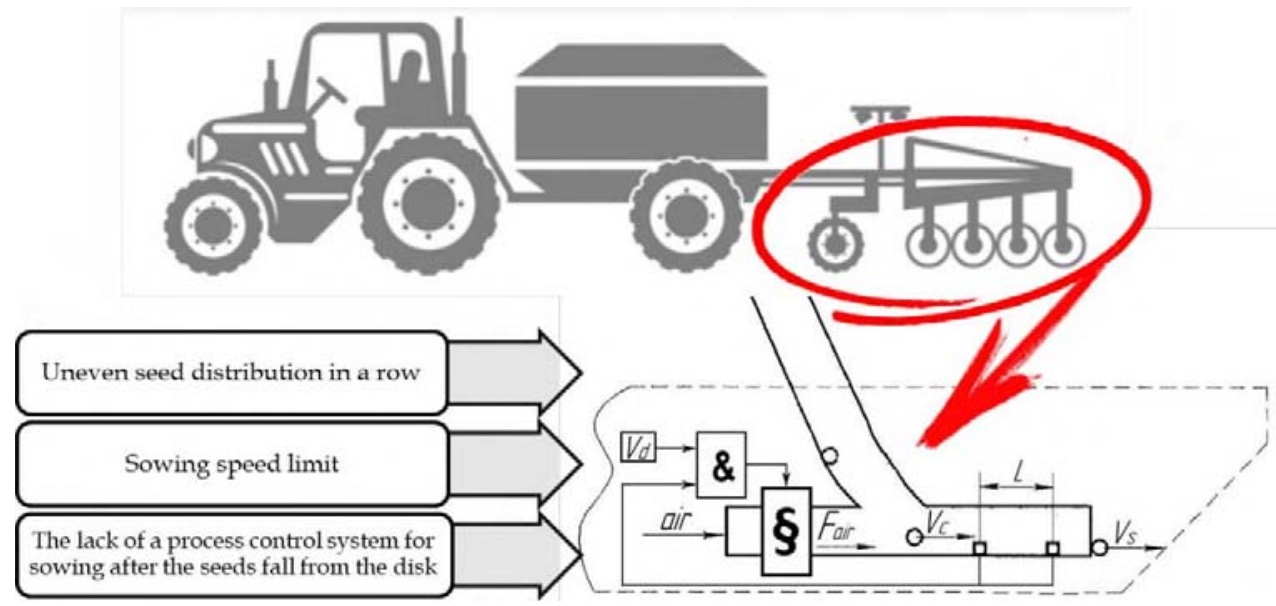

Fig. 2. Diagram of the improved sowing device with an automatic system for control and monitoring of sowing quality.

The questions of the efficiency of the seeding unit were more thoroughly considered by us in [10].

Timely and reliable evaluation of the performance indicators is an integral link in the system of functioning of any agricultural machinery. The assessment of efficiency is a topical issue by itself and in relation to sowing operations is important in terms of accuracy and time spent on their implementation

In accordance with [11-13], the efficiency is defined as the ratio of the achieved results of the activity to the expenses made to achieve this result. Then the assessment of the efficiency of any processes is reduced to determining the performance of the activity and the made expenses.

In [3], we considered some aspects of assessing the performance of processes of mechanized harvesting of grain crops. Figure 3 schematically shows the main factors leading to inefficiencies of combine harvesting processes. 


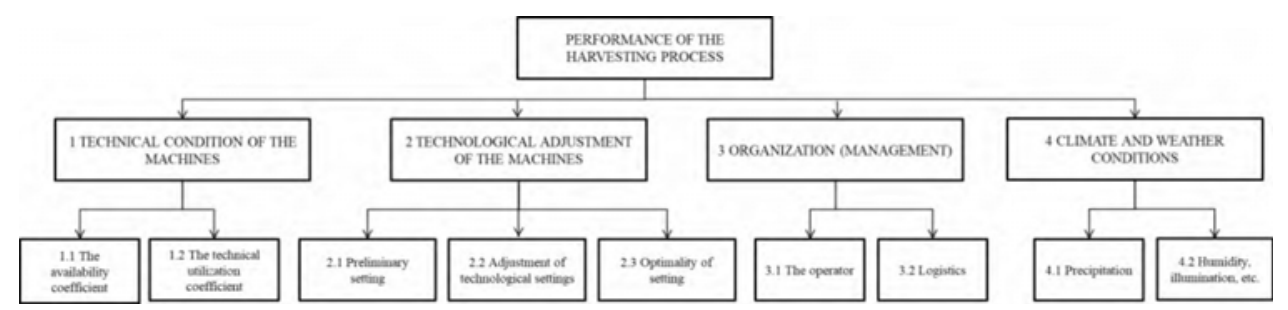

Fig. 3. The reasons for the inefficiencies of grain harvesting processes.

\section{Research status and work relevance}

Based on the data in $[3,14,15]$ it is possible to describe the factors influencing the decrease in the efficiency of combine harvesting processes by the following ratios. Here we should like to pause for a moment and tell our readers that major part of coefficients is almost similar and will be demonstrated on the example of combine harvesting.

The coefficient of the weather conditions

$$
C_{W}=\frac{t_{d n i h}}{t_{d n i h}+t_{d n a h}}
$$

where $C_{\mathrm{W}}$ - the coefficient of weather conditions;

$t_{\text {dnih }}$ - the average time during which the weather and climate conditions did not interfere with the performance of mechanized harvesting;

$t_{\text {dnah }}$ - the average time during which the weather and climate conditions did not allow mechanized harvesting.

The availability coefficient

$$
C_{A}=\frac{\overline{\mathrm{T}}_{F}}{\overline{\mathrm{T}}_{F}+\overline{\mathrm{T}}_{R}},
$$

where $C_{A}$ - the availability coefficient;

$\overline{\mathrm{T}}_{F}$ - the average failure interval;

$\overline{\mathrm{T}}_{R}-$ the average recovery time.

The technical utilization coefficient

$$
C_{T U}=\frac{\overline{\mathrm{T}}_{F}}{\overline{\mathrm{T}}_{F}+\overline{\mathrm{T}}_{R}+\overline{\mathrm{T}}_{M}},
$$

where $C_{T U}$ - the technical utilization coefficient;

$\overline{\mathrm{T}}_{M}$ - the average maintenance time.

The coefficient of technological setting (adjustment) $\left(\mathrm{C}_{\mathrm{S}}\right)$ characterizes the time spent on setting and adjusting the operating modes of the working bodies of the combine harvesters.

$$
C_{S}=\frac{\overline{\mathrm{T}}_{\text {work }}}{\overline{\mathrm{T}}_{\text {work }}+\overline{\mathrm{T}}_{S}+\overline{\mathrm{T}}_{A d}},
$$

where $\overline{\mathrm{T}}_{\text {work }}-$ the average time of useful work;

$\overline{\mathrm{T}}_{S}$ - the average time spent on setting up the combine;

$\overline{\mathrm{T}}_{A d}$ - the average time spent on adjusting technological settings. 
The load coefficient $\left(C_{L}\right)$ shows how fully the declared throughput of the combine is used.

$$
C_{L}=\frac{q_{a c t}}{q}
$$

where $q$ - the declared throughput of the combine harvester, $\mathrm{kg} / \mathrm{s}$;

$q_{a c t}-$ the actual throughput of the combine harvester, $\mathrm{kg} / \mathrm{s}$.

$$
q_{a c t}=\frac{S_{a} \times Y\left(1+C_{R}+C_{D}\right)}{t_{h}}
$$

where: $S_{a}$ - the area (Hectares), actually harvested during continuous operation $t_{h}$ (hours); $\mathrm{Y}$ - the yield, tons/ha;

$C_{R}$ - the ratio of straw and grain by weight (standard value is $1.5: 1$ );

$C_{D}$ - the dockage of the crop stand by weight.

Simplified calculation of the load coefficient is

$$
C_{L}=\frac{v_{a c t}}{v_{\mathrm{p}}}
$$

where $v_{\text {act }}$ - the actual speed of the combine during harvesting, $\mathrm{km} / \mathrm{h}$.

In the Russian standards for testing grain harvesters, the concept of working speed is established, which corresponds to the computed capacity.

$$
v_{\mathrm{p}}=\frac{10 \times W_{c}}{B_{r g} \times Y_{\text {prel }}},
$$

where $W_{c}$ - the computed capacity of the combine, $\mathrm{t} / \mathrm{h}$;

$Y_{\text {prel }}$ - preliminary grain yield excluding losses after the combine, tons/ha;

$B_{r g}$ - structural width of the reaper grab, $\mathrm{m}$.

The organizational downtime coefficient $\left(C_{O}\right)$ :

$$
C_{O}=\frac{\overline{\mathrm{T}}_{\text {work }}}{\overline{\mathrm{T}}_{\text {work }}+\overline{\mathrm{T}}_{\text {org }}},
$$

where $\overline{\mathrm{T}}_{\text {work }}-$ the average time of useful work;

$\overline{\mathrm{T}}_{\text {org }}$ - the average downtime for organizational reasons:

$$
\overline{\mathrm{T}}_{\text {org }}=t_{\text {oper }}+t_{\text {ref }}+t_{\text {log }}+t_{\text {tran }}
$$

where $t_{\text {oper }}$ - the average downtime associated with the operator (lunch break, shift, including the time when harvesting can be performed, but work is not done due to excess workload on the operator, etc.);

$t_{r e f}$ - the average downtime associated with refueling;

$t_{l o g}$ - the average downtime associated with waiting for the machines to unload grain;

$t_{\text {tran }}$ - the average time of vehicles transportation from field to field and to places of permanent location (brigades, field camps, machine parks, garages, etc.)

\section{Results and discussion}


The generalized observation results obtained during harvesting of grain crops in the summer of 2019 and 2020 are presented in Table 1.

Table 1. The results of determining the performance of grain harvesting processes in 2019 and 2020

\begin{tabular}{|c|l|r|r|}
\hline \multirow{2}{*}{ № } & \multicolumn{1}{|c|}{ Coefficient name } & \multicolumn{2}{c|}{ Coefficient value } \\
\cline { 3 - 4 } & & \multicolumn{1}{|c|}{$\mathbf{2 0 1 9}$} & \multicolumn{1}{c|}{$\mathbf{2 0 2 0}$} \\
\hline 1 & Planned productivity $\left(\mathrm{S}_{\mathrm{P}}\right)$, ha/combine & 1413.18 & 1433.26 \\
\hline 2 & The weather conditions coefficient $\left(\mathrm{C}_{\mathrm{W}}\right)$ & 0.58 & 0.53 \\
\hline 3 & The technical utilization coefficient $\left(\mathrm{C}_{\mathrm{TU}}\right)$ & 0.83 & 0.84 \\
\hline 4 & The technological setting coefficient (adjustment) $\left(\mathrm{C}_{\mathrm{S}}\right)$ & 0.86 & 0.86 \\
\hline 5 & The load coefficient $\left(\mathrm{C}_{\mathrm{L}}\right)$ & 0.80 & 0.77 \\
\hline 6 & The organizational downtime coefficient $\left(\mathrm{C}_{\mathrm{O}}\right)$ & 0.60 & 0.59 \\
\hline 7 & The actual performance $\left(\mathrm{S}_{\mathrm{a}}\right)$, Ha/combine & 280.82 & 249.30 \\
\hline
\end{tabular}

The coefficients differing in the smallest values correspond to the groups of the factors that most strongly affect the decrease in the performance. The analysis of the reasons for the decrease in the performance and, as a consequence, the efficiency of combine harvesting processes should begin with these groups of factors.

The strongest decrease in the performance and efficiency of combine harvesting processes happens due to the weather conditions (coefficient value is 0.53 ), organizational reasons $(0.59)$ and nonoptimal loading of the combines $(0.77)$.

The weather conditions are an uncontrollable factor, therefore, it is pointless to consider this group of reasons for a decrease in the performance.

Among the organizational reasons for the inefficiencies of the harvesting process, the downtime associated with waiting for the machines for grain unloading and the loss of time for the transportation of the equipment prevails. At the same time, both of these components increase with the distance of the harvested fields from the grain storage places.

The load coefficient $\left(\mathrm{C}_{\mathrm{L}}\right)$ of the combine harvesters also has quite low value. The reason for this, in many respects, is the well-established practice of limiting the maximum speed of the combine harvesters $\left(v_{\text {act }}\right)$, based on the subjective judgments of agronomists, and not on the basis of the objective indicators of the quality of the technological process of grain crops harvesting (grain loss, dockage, crushing, etc.). Such an approach leads to the fact that the maximum speed of movement is set the same for all the combines and harvested fields, despite the differences in the technical characteristics, the condition of the machines, and the state of the harvested crops.

A more detailed analysis of the group of the indicators of the technical condition of the machines $\left(\mathrm{C}_{\mathrm{TU}}\right)$ demanded to divide all the observed machines into 4 groups depending on the terms of operation:

- group I - from 0 to 2 years of the operation (the period of the manufacturer's warranty);

- group II - from 2 to 5 years of operation;

- group III - from 5 to 10 years of operation;

- group IV - more than 10 years of operation.

The following values of the technical utilization coefficient for these groups of the machines were obtained (figure 4):

- group I - 0.93;

- group II - 0.94;

- group III - 0.89;

- group IV - 0.71 . 


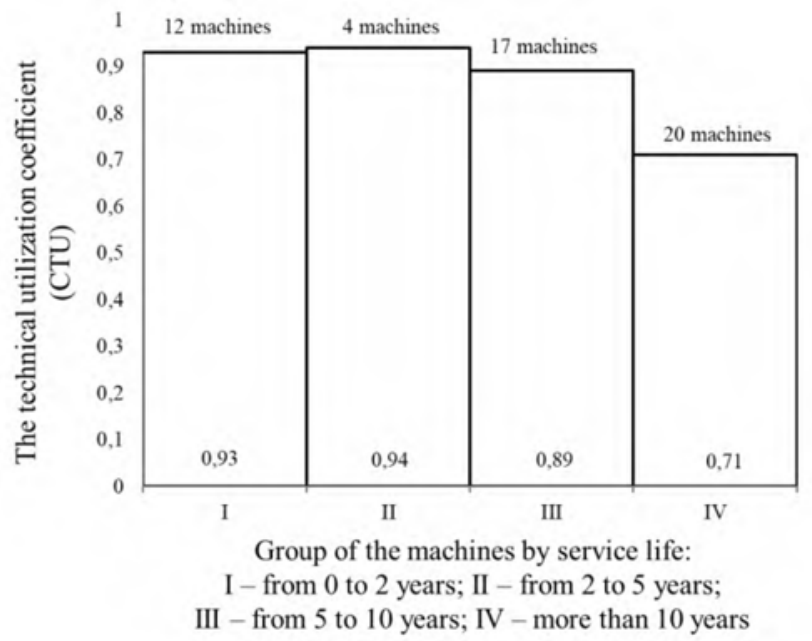

Fig. 4. The dependence of the value of the technical utilization coefficient of the machines on the service life.

It can be seen from the graph in the figure that the group of the machines with a service life of more than 10 years (group IV) is characterized by a significantly lower value of the technical utilization coefficient.

Observations of processes of daily maintenance of the combine harvesters have shown that about $20 \%$ of the time ( 0.25 hours out of 1.25 hours) for daily maintenance is spent on waiting in line at the posts with a compressor unit

\section{Conclusions}

The results of the analysis of the reasons for the inefficiencies of grain sowing and harvesting processes allow us to make the following conclusions:

1. The introduction of an automated system of quality control and monitoring into the seeding unit increases the even distribution of the tilled crops seeds in a row during sowing and allows to perform technological control of the sowing device operation during sowing. 2. When determining the working speed of the combine harvesters, one should be guided by the technical characteristics and technical condition of the machines, as well as the values of the objective indicators of the quality of the technological process of mechanized harvesting of grain crops (grain loss, crushing, trash, etc.).

3. The increase in the number of the posts for daily maintenance of the combines will reduce the time spent on maintenance by up to $20 \%$.

4. The combines with a service life of more than 10 years are characterized by a significantly lower value of the technical utilization coefficients, which makes it advisable to consider the issues related to the renewal of the machine park.

\section{References}

1. V. Dimitrov, L. Borisova, I. Nurutdinova, AISC, 875, DOI: 10.1007/978-3-030-01821425

2. V. Dimitrov, L. Borisova, I. Nurutdinova, V. Pakhomov, V. Maksimov, MATEC Web Conf., 226, 04023 (2018) DOI: 10.1051/matecconf/201822604023 
3. V. Kataev, I. Markvo, K. Khubiian, V. Dimitrov, E3S Web of Conferences, 175, 05005 (2020) DOI: $10.1051 / \mathrm{e} 3$ sconf $/ 202017505005$

4. L. Borisova, V. Dimitrov, I. Nurutdinova, AISC, 680, DOI: 10.1007/978-3-319-683249_11

5. S. K. Nielsen, L. J. Munkholm, M. Lamandé, M. Nørremark, G. T. C. Edwards, O. Green, Computers and Electronics in Agriculture, 144 (2018) DOI: 10.1016/j.compag.2017.12.008

6. S. Kamgar, F. Noei-Khodabadi, S. M. Shafaei, Information Processing in Agriculture, 2 (2015) DOI: 10.1016/j.inpa.2015.08.001

7. V. Kataev, I. Markvo, K. Khubiian, E. Zubrilina, E3S Web of Conferences, 175, 05034 (2020) DOI:10.1051/e3sconf/202017505034

8. A. A. Al-Mallahi, K. Takashi, IFAC Proceedings Volumes, 46(18) (2013) DOI: 10.3182/20130828-2-SF-3019.00011

9. H. Goyal, N. Joshi, C. Sharma, Procedia Computer Science, 132 (2015), DOI: 10.1016/j.aaspro.2015.12.010

10. I. Markvo, E. Zubrilina, V. Novikov, E3S Web of Conferences, 126, 00054 (2019) DOI:10.1051/e3sconf/201912600054

11. D. Kortenbruck, H. W. Griepentrog, D. S. Paraforos, Computers and Electronics in Agriculture, 140, 227-236 (2017) DOI: 10.1016/j.compag.2017.05.039

12. A. Utamima, T. Reiners, A. H. Ansaripoor, Biosystems Engineering, 184, 166-180 (2019) DOI: 10.1016/j.biosystemseng.2019.06.001

13. T. U. Rehman, Md. S. Mahmud, Y. K. Chang, J. Jin, J. Shin, Computers and Electronics in Agriculture, 156, 585-605 (2019) DOI: 10.1016/j.compag.2018.12.006

14. E. Zubrilina, I. Markvo, V. Novikov, A. Beskopylny, L. Vysochkina, D. Rudoy, A. Butovchenko, IOP Conf. Ser.: Earth Environ. Sci., 403, 012063 (2019) DOI:10.1088/1755-1315/403/1/012063

15. L. Borisova, V. Dimitrov, Mordovia University Bulletin, 27, 178-189 (2017) DOI: 10.15507/0236-2910.027.201702.178-189 